\title{
Temporal variation in growth rates and reproductive parameters in the small near-shore tropical squid Loliolus noctiluca; is cooler better?
}

\author{
George D. Jackson ${ }^{1, *}$, Natalie A. Moltschaniwskyj ${ }^{2}$ \\ ${ }^{1}$ Institute of Antarctic and Southern Ocean Studies, University of Tasmania, PO Box 252-77, Hobart, Tasmania 7001, Australia \\ ${ }^{2}$ School of Aquaculture, Tasmanian Aquaculture and Fisheries Institute, University of Tasmania, Locked Bag 1-370, \\ Launceston, Tasmania, 7250, Australia
}

\begin{abstract}
Seasonal growth rates and size- and age-at-maturity were analysed for the small nearshore tropical loliginid squid Loliolus noctiluca off North Queensland, Australia, over a period of 2 yr. Age of individuals was determined using daily statolith increments. The life cycle of L. noctiluca off North Queensland was just over 4 mo. Analysis of growth found that growth was non-asymptotic, and the form of the curve; exponential, linear or log-linear, depended on sex and season that individuals were caught. Winter-caught individuals were the fastest growing and achieved the largest size compared with summer or autumn-caught individuals. Furthermore, females grew faster than males during the winter. The patterns of growth of L. noctiluca were compared between tropical North Queensland and temperate New South Wales. The temperate individuals lived longer and had slower growth rates. There was also a marked seasonal influence on the onset of sexual maturity among the North Queensland population, with the fastest growing winter-caught individuals maturing later than the autumn or summer individuals. L. noctiluca has a large latitudinal range from New Guinea to Tasmania, this study, and published work, suggests a trend towards increased lifespan and decreased growth rate with increasing latitude.
\end{abstract}

KEY WORDS: Statoliths $\cdot$ Age $\cdot$ Growth rates $\cdot$ Squid $\cdot$ Reproduction

\section{INTRODUCTION}

Significant advances have been made in the last decade with regard to our understanding of the rates and form of squid growth. An important breakthrough has been the application of daily statolith increments (e.g., Rodhouse \& Hatfield 1990a, Jackson 1994) to estimate size-at-age of individuals. Many species of squid are now known to have short lifespans and generally indeterminate, non-asymptotic growth. The novel form of growth (compared to their teleosts counterparts) along with short lifespans and resulting rapid turnover in populations make squids unique marine models for studying the relationship between growth and population dynamics.

*E-mail: george.jackson@utas.edu.au
Given the unique features of cephalopod growth, it is interesting to study growth dynamics of both tropical and particularly small-bodied species. These small, warm water species are pushing the limits of the efficiencies of cephalopod growth (e.g., Jackson 1989, Young \& Mangold 1993, Arkhipkin 1994, 1998). Such species provide insights into the mechanisms that govern short lifespans, rapid growth and multiple subannual populations.

Although our knowledge has increased in regard to squid growth, questions remain as to how applicable any model of growth may be if a squid grows under differing environmental conditions. Research continues to reveal that squid growth can be greatly modified by temperature or season of hatching (Rodhouse \& Hatfield 1990b, Jackson \& Choat 1992, Forsythe 1993, Brodziak \& Macy 1996, Dawe \& Beck 1997, Jackson et 
al. 1997, Hatfield 2000, Forsythe et al. 2001) as well as food supply (Jackson \& Moltschaniwskyj 2001). However, our understanding of the causes of plasticity in squid growth is still far from complete.

Forsythe (1993) was instrumental in developing theories about the influence of temperature on squid growth. His working hypothesis based on laboratory data suggest that relatively small changes in temperature (especially during the juvenile exponential growth phase) can have dramatic consequences on adult body size with a small increase in temperature dramatically increasing growth rate.

Field studies on Lolliguncula brevis in the Gulf of Mexico (Jackson et al. 1997) and Loligo gahi on the Patagonian Shelf (Hatfield 2000) tested the Forsythe (1993) hypothesis. In both of these studies, the influence of seasonal temperature variation on the growth of different cohorts was assessed. Both of these studies support Forsythe's hypothesis (1993) and show that squid hatching in warmer periods do 'out grow' their cooler-hatched counterparts. Forsythe et al. (2001) furthermore unequivocally demonstrated this same temperature effect on growth using temperature-controlled grow-outs of known age squid hatched and grown in captivity. Grist \& des Clers (1998) extended the Forsythe hypothesis and developed a model that explains how differing seasonal growth rates could affect the size distribution in populations of L. gahi.

It is also important to consider how seasonal differences in growth may reflect important parameters in squid growth models. Jackson (1998) highlighted the need for using discrete sets of size-at-age data when assessing the form of squid growth. If data are pooled over too broad a period or covering several seasons, it is possible to mask the form of growth completely in a short lived squid. However, if a particular model of growth has been developed for a squid species based on size-at-age data for one period of time, can we assume that this model would apply to other times or seasons?

This study was undertaken to explore seasonal variation in growth using statolith ageing of the small squid Loliolus noctiluca in tropical waters off North Queensland Australia. We wanted to explore issues of seasonal influences on growth rates, lifespans, maturity rates and the form of growth. More comprehensive data sets are needed in the ongoing development of robust models of squid growth. L. noctiluca appeared to be a good model organism for such a study. It is a small near-shore species which is easily accessible, has a short lifespan (which means there are a number of generations in any single year), has a clear statolith increment structure and statolith increments have been shown to be laid down daily (Jackson 1990, Dimmlich \& Hoedt 1998). Based on current knowledge, we hypothesised that the warm tropical summer water temperatures would be reflected in faster growth rates and shorter lifespans in this small near-shore loliginid squid.

Loliolus noctiluca has a wide distribution ranging over 35 degrees in latitude from New Guinea to Tasmania (Lu et al. 1985). This distribution and its nearshore habitat suggest that it is tolerant of a wide range of conditions and may therefore modify its lifestyle in response to varying ambient temperatures. We focused our sampling regime on obtaining replicate samples throughout the year to explore seasonal growth in a tropical environment off Townsville, North Queensland, Australia. For comparative purposes we also obtained squid from temperate waters much farther south off Newcastle, New South Wales.

\section{METHODS}

Squid sampling. Samples of Loliolus noctiluca were collected in Cleveland Bay (19 $\left.11^{\circ} \mathrm{S}, 146^{\circ} 56^{\prime} \mathrm{E}\right)$ Australia, using paired otter trawl nets $(11 \mathrm{~m}$ gape, $3.8 \mathrm{~cm}$ mesh) towed for approximately $20 \mathrm{~min}$ off the RV James Kirby. Samples were taken during 4 seasonal periods (spring - September, summer - December, autumn - March/ April and winter - June/July) in 1996 and 1997. Sampling consisted of trawling for a day on each of the 8 sampling periods. In addition, during March, the James Cook University's School of Marine Biology collected L. noctiluca during teaching trips each year. All L. noctiluca samples were preserved in approximately $75 \%$ ethanol.

This sample of Loliolus noctiluca was also obtained from trawling further south along the Australian east coast off Stockton Beach, (approximately $33^{\circ} \mathrm{S}$ ) near Newcastle, New South Wales on 24 May 1998. These individuals were obtained through the commercial fishery and were frozen.

All squid were processed in the laboratory where statoliths were removed for ageing. Measurements taken included, sex, maturity stage (after Jackson et al. 1997), mantle length (ML), total wet weight, and gonad weight. As the Newcastle squid were frozen and measures were made on frozen squid, we needed to apply a correction factor so measurements were comparable to the alcohol fixed Townsville squid. To obtain this correction, a subsample of defrosted Newcastle squid were weighed, measured (ML) whilst fresh, and preserved in ethanol for several weeks, then weighed and measured again. There was a strong correlation between the fresh and preserved values (ML $\mathrm{r}=0.99, \mathrm{n}=20$; weight $\mathrm{r}=0.94$, $\mathrm{n}=20$ ). Therefore, it was with confidence that we used the linear regression equation between the freshly defrosted and preserved measurements to adjust the measurements taken on defrosted individuals. 
Statolith ageing. The statoliths of the Townsville squid were removed from ethanol preserved individuals, and mounted directly in the thermoplastic cement Crystal Bond. As the statoliths are translucent they did not require any grinding or polishing and increment counts could be taken directly on unground statoliths. Counting of increments was done using a high power microscope with a video camera attached to a PC computer with a frame grabber card. Increment counts were taken on live images off the computer screen. The estimated age was taken as the mean of 2 consecutive counts that varied by less than $10 \%$ of the mean. If the 2 counts were greater than $10 \%$, a third count was taken and the mean age then calculated from all 3 counts. Replicate counts were generally very close and less than $5 \%$ of statoliths required a third count. The statoliths of the Newcastle squid were not as translucent and required grinding and polishing (see Jackson \& Moltschaniwskyj 1999) on both sides to allow increment counts to be made.

Growth curves were generated using size-at-age (wet wt or ML) information. The shape of the growth curve was determined using the generalised growth curve of Schnute (1981) as per the description provided by Brodziak \& Macy (1996). The generalised growth model includes exponential, linear, and asymptotic which allowed us to differentiate between asymptotic and non-asymptotic fits, and between exponential and power fits of the size-at-age information.

Males and females were segregated according to the austral season they were caught; winter, spring (not analysed due to small numbers of individuals; 10 males, 7 females), summer and autumn. For every combination of sex and season the Schnute generalised model was used to determine the growth model that best described the data.

We were interested in comparing the growth rates for combinations of sex and season of capture, however direct comparisons could only be made between groups that had the same type of growth models e.g. linear versus linear. Where groups of individuals had different growth models, but a comparison was of interest, e.g. females among the 3 seasons, or between sexes within a season, we determined if a single growth model to 2 or more groups was a better fit than 2 or more separate models. For example if females among the 3 seasons had different growth models, then a single model combining all the females was generated and it was then determined if this single model was a better fit than the 3 separate models. To do this comparison, we used an analysis of the residual sums of squares (Chen et al. 1992).

The relationship between length and weight provides a useful indicator of the condition of individuals in the population. A 2-way analysis of covariance (ANCOVA) with sex and season as the factors of interest, and age as a covariate was used to determine if the length-weight relationships, and hence condition, differed among the sex-season groups. Where a significant factor was detected the $95 \%$ confidence limits were used to determine where the differences were occurring.

Reproductive analysis. We were interested in exploring the trends in maturity for each sex throughout the year. Therefore, the frequency of individuals in each maturity stage among the seasonal samples was analysed using a chi-square test of independence for males and females separately.

The relationship between body weight and testis weight was linear for males so it was possible to use an ANCOVA to compare the relationship between testis weight and body weight among the seasons. A linear analysis was not possible for the females since the ovary weight data was so heavily skewed due to the large number of very immature females with very small ovaries. As transforming the data did not overcome the problem of excessive skewness, we analysed females who had commenced gonad growth, as evidenced by gonad weights of greater than or equal to $0.09 \mathrm{~g}$. This allowed us to use an ANCOVA to compare the change in ovary weight with body size among the seasons.

\section{RESULTS}

All combinations of sex and season showed nonasymptotic growth. In other words, there was no evidence of an inflection in the size-at-age information to indicate that growth ceased at the maximum size. However, the form of the size-at-age curves generated was not consistent among the combinations of sexes and season; power, linear, log-linear and exponential growth was evident. Exponential growth represents a constant increase in size relative to body size, i.e., there is no change in the specific growth rate as individual size increases. In contrast, in the log-linear, linear and power growth models the specific growth rates slow as individuals get bigger. This decline in the specific growth rate with size is fastest in those populations with log-linear growth curves, while in those populations with power growth curves the changes in the specific growth rate with body size is slowest. The speed at which the specific growth rate slows with body size has important implications in energy dedicated to growth and in particular the allocation of energy to reproduction.

Although it was not possible to model growth of the spring-sampled squid, it appeared that they may have been slower growing than individuals from the other seasons. They were also generally smaller and weighed less than individuals captured at other sea- 
sons. Two of the spring females were also the oldest individuals captured, 118 and $121 \mathrm{~d}$, however, the sizes of these 2 female squid were only $57.9 \mathrm{~mm} \mathrm{ML}, 13.40 \mathrm{~g}$ and $84.5 \mathrm{~mm} \mathrm{ML}, 26.66 \mathrm{~g}$, respectively.

\section{Growth—dorsal mantle length}

The females showed a range of growth forms among the seasons of capture, including exponential, linear and log-linear (Fig. 1). Generating a single growth curve for summer and winter females together provided a poorer fit of the data than growth curves for each group separately $(F=6.28$, df 3,133 , p < 0.001).

The males all grew log-linearly (Fig. 1) but there was a significant difference among the 3 seasons $(F=39.17$, df $6,217, \mathrm{p}<0.001)$. The autumn and winter-caught males grew at a very similar rate so a single growth model was generated for these squid $(\ln (y)=43.14$, $\ln (x)=132.62, \mathrm{n}=126, \mathrm{r}^{2}=0.75, \mathrm{SE}_{\mathrm{b}}$ [standard error of growth rate] $=3.44$ ); however, they grew on average $13 \%$ faster than their summer-caught counterparts.

\section{Growth-weight}

Female Loliolus noctiluca all had power growth curves (Fig. 2); however, there were significant differences among the 3 growth curves $(F=27.35$, df 6,188 , $\mathrm{p}<0.001)$. Winter and autumn females had similar growth rates $(F=1.58$, df $3,120, p=0.199)$ and could be described by a single power growth curve $(\ln (y)=4.03$, $\left.\ln (x)=15.20, \mathrm{n}=97, \mathrm{r}^{2}=0.74, \mathrm{SE}_{\mathrm{b}}=0.24\right)$; however females caught during the summer months grew on average $66 \%$ slower $(F=7.04$, df 3,120 p < 0.001).

Male Loliolus noctiluca grew either linearly or loglinearly (Fig. 2), and the growth rates of the 3 groups were significantly different $(F=81.74$, df $6,217, \mathrm{p}<$ 0.001). The relationship between growth rates and season was similar to that of females, with the summercaught males growing on average $64 \%$ slower than their winter-caught counterparts (Fig. 2).

\section{Comparison between the sexes \\ Dorsal mantle length}

The autumn males and females could not be compared because the shape of the growth curves were different, i.e., exponential versus loglinear. There were significant differences between the male and female growth curves in both summer $(F=$ 7.65, df 3,194, p < 0.001) and winter $(F=7.28$, df 3,88 , p < 0.001). During the summer males had a log-linear form of growth, compared with the females that showed linear growth. In contrast, in the winter both males and females had log-linear growth curves; however females grew almost twice as fast as the males (Fig. 1).

\section{Weight}

We were unable to make comparisons in growth rates because in each season the sexes had a different form of the weight-at-age relationship
Fig. 1. The relationship between age and dorsal mantle length for Townsville female and male Loliolus noctiluca for the 3 seasonal periods. $\mathrm{SE}_{\mathrm{b}}=$ standard error of the growth rate 
(Fig. 2). However, it was possible to determine if a single growth curve combining both males and females was a better model than the separate model for each sex for each season. In each season, it was found that growth of the individuals was better if a growth model was fitted to the sexes separately rather than together $\left(F_{\text {autumn }}=\right.$ 13.84, df $3,123, \mathrm{p}<0.001 ; F_{\text {winter }}=$ 25.12, df $3,88, \mathrm{p}<0.001, F_{\text {summer }}=$ 18.68, df 3,194, p < 0.001).

\section{Length-weight relationships}

The slopes of the length-weight relationships ranged from 2.09 to 2.70 (Fig. 3), and these differed significantly among the combinations of sex and season $(F=5.67$, df 2,412 , $\mathrm{p}=0.004)$. During the summer and autumn, males and females had very similar length-weight relationships; however during the winter a $30 \%$ difference was seen between males and females with the females in better condition (Fig. 3). Winter females did not appear to be heavier for their length compared with females and males in the other seasons. It was also notable that winter males were variable in their length-weight relationship compared with the other groups of individuals (Fig. 3).
Females
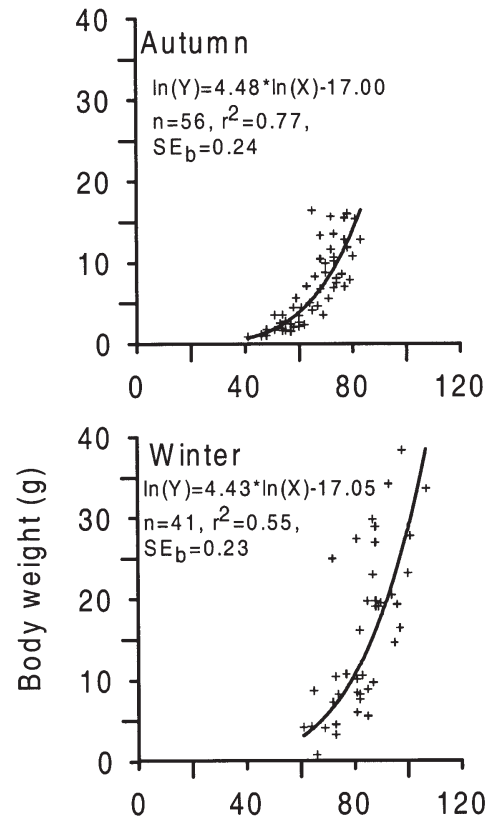

40 Jummer

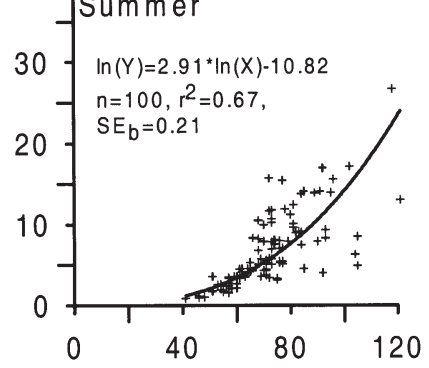

Males

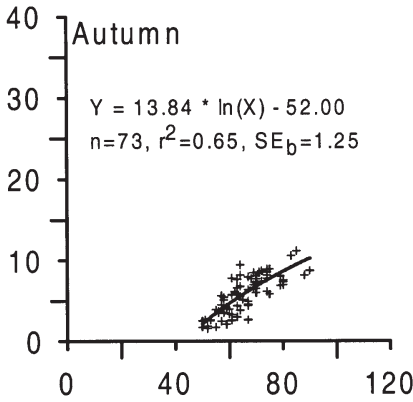

40 W inter
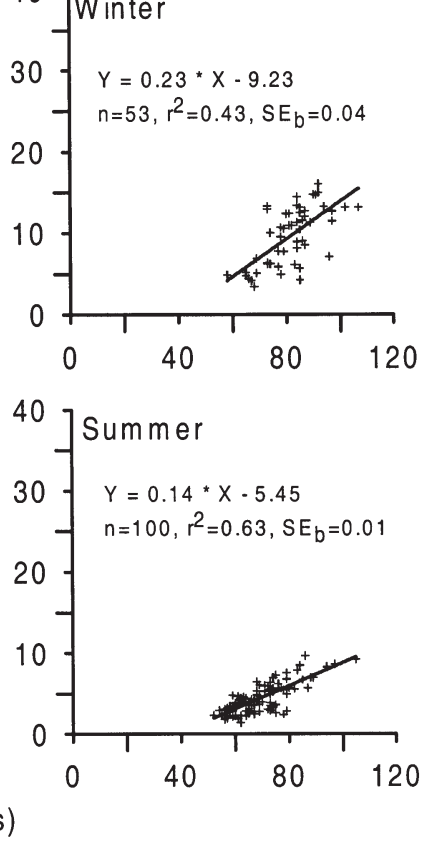

Fig. 2. The relationship between age and total body weight for Townsville female and male Loliolus noctiluca for the 3 seasonal periods. $\mathrm{SE}_{\mathrm{b}}=$ standard error of the growth rate

\section{Comparison of Townsville and Newcastle growth}

Both male and female Newcastle squid had log-linear patterns of growth for both mantle length and weight (Figs 4 \& 5). Newcastle females grew 3 times faster than Newcastle males, in mass $(F=38.08$, df $3,94, \mathrm{p}<0.001)$ and twice as fast in length $(F=24.55$, df $3,94, p<0.001)$. Despite the dramatic differences in growth rates between the sexes, there was no difference in the length-weight relationships between the males and females $(F=3.35$, df $1,96, \mathrm{p}=0.07)$ suggesting the differences in growth were not mirrored in the condition of the squid.

There were significant differences in growth between the Newcastle and Townsville autumn-caught squid for both sexes (Figs 4 \& 5). The Newcastle data was also more variable which resulted in much lower $\mathrm{r}^{2}$ values compared to the Townsville data. The weight-

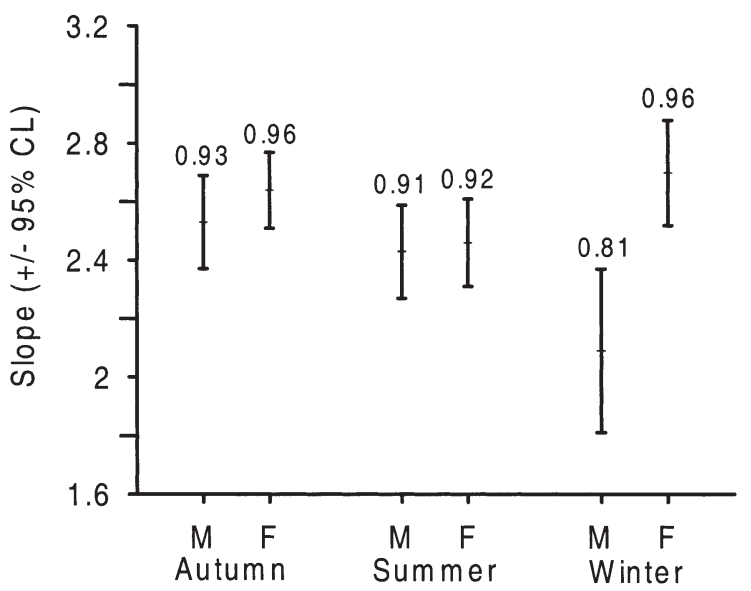

Fig. 3. The slope ( $\pm 95 \%$ confidence limits) of the lengthweight relationship for every combination of sex and season. The value above each point is the $\mathrm{r}^{2}$ value for each relationship. $\mathrm{M}=$ male, $\mathrm{F}=$ female 


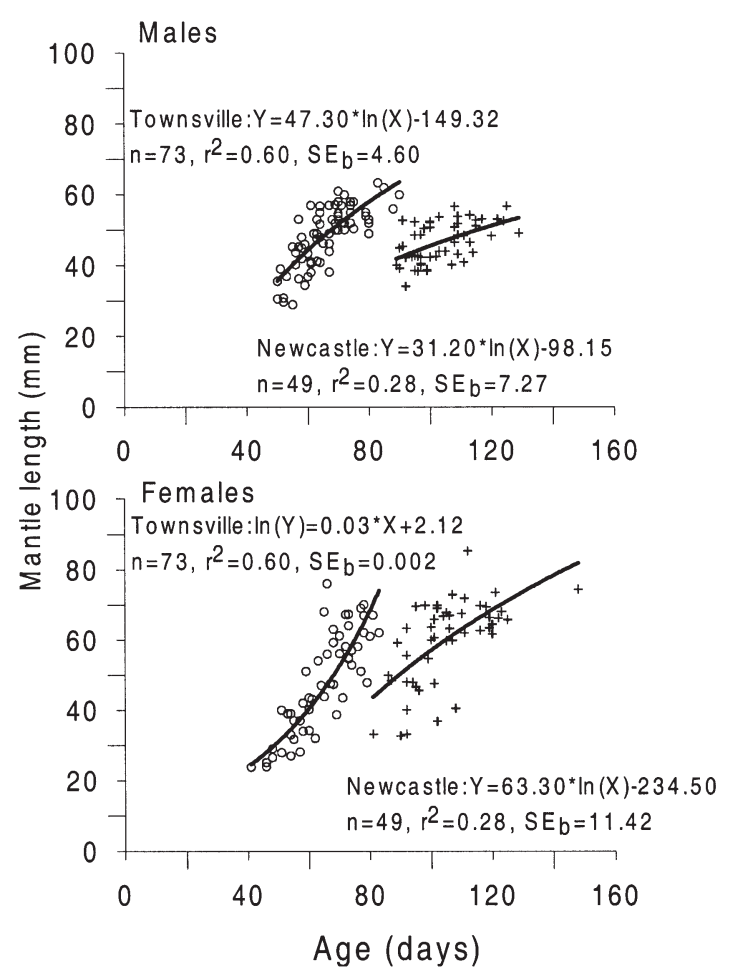

Fig. 4. The relationship between age and dorsal mantle length for Newcastle and Townsville autumn-caught males and females of Loliolus noctiluca. $+=$ Newcastle, $\mathrm{O}=$ Townsville. $\mathrm{SE}_{\mathrm{b}}=$ standard error of the growth rate

at-age and length-at-age relationships between the males were almost identical in both elevation and slope (Figs. 4 \& 5); however, it was not possible to fit a single growth curve to the combined data set (weight $F=7.59$, df $3,117, \mathrm{p}<0.001$; length $F=25.32$, df 3,117, $\mathrm{p}<0.001$ ). This was because although the average size of the squid was very similar, on average the Newcastle males were $56 \%$ older than the Townsville males. Therefore, despite both samples having similar growth rates the Newcastle males were larger and must have grown slower as immature individuals.

Females from the 2 locations had different ML-atage relationships (Fig. 4), with the Townsville autumn females displaying exponential growth, while the Newcastle females grew log-linearly. There were also differences in the growth in weight; the Townsville autumn females displayed power growth, while the Newcastle females a log-linear growth curve (Fig. 5). For both length- and weight-at-age it was not possible to fit a single growth curve to both groups of females (weight $F=33.03$, df $3,100, \mathrm{p}<0.001$; length $F=10.38$, df $3,100, p<0.001)$. As for the males, there was a dramatic difference in the age of the females, with the Newcastle females on average being $65 \%$ older. However, unlike the males, the Newcastle females were on average more than twice the weight and $21 \%$ longer

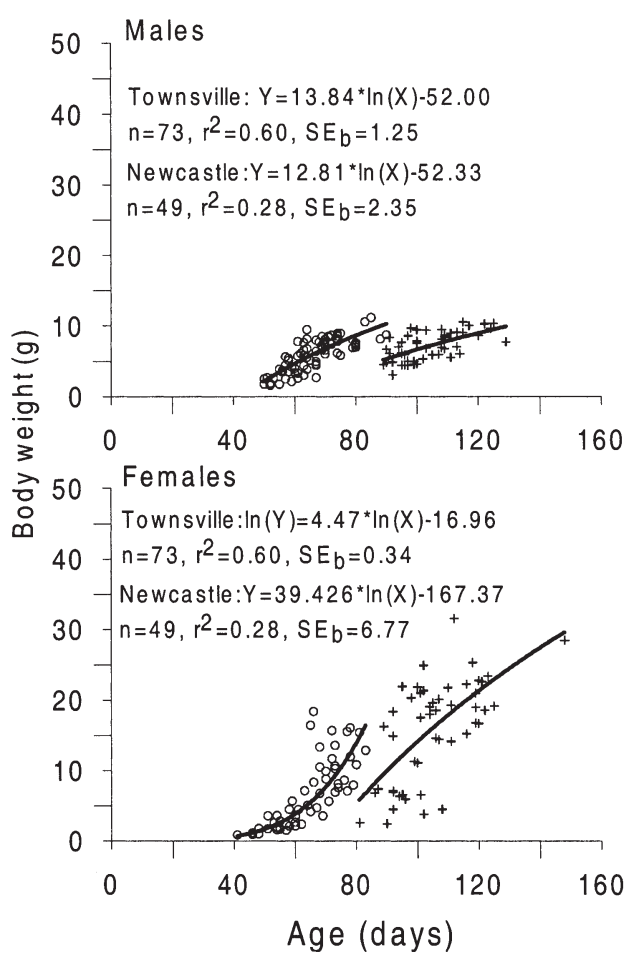

Fig. 5. The relationship between age and body weight for Newcastle and Townsville autumn-caught individuals of Loliolus noctiluca. $+=$ Newcastle, $0=$ Townsville. $\mathrm{SE}_{\mathrm{b}}=$ standard error of the growth rate

than the Townsville females. The difference in the form of the growth curve between the 2 groups of females suggested that the growth rate of the larger Newcastle females was slowing dramatically compared with the Townsville females.

Interestingly, there was no significant difference in the length-weight relationships (Fig. 6) between the Newcastle and Townsville males $(F=1.52$, df $1,120, \mathrm{p}=$ $0.22)$ or females $(F=0.41$, df $1,102, \mathrm{p}=0.52)$. This suggests that despite disparity in growth rates there is no significant difference in the condition of the squid.

\section{Reproductive analysis}

Frequency analysis

For both males and females, the number of individuals at each maturity stage was dependent upon the season of sampling (males $\chi^{2}=59.9$, df $8, \mathrm{p}<0.001$; females $\chi^{2}=72.4$, df $8, p<0.001$ ). It was evident for both sexes that more stage IV and V (i.e. mature squid) were seen during winter and autumn, while more stage II and III (i.e. immature or maturing) squid were seen in summer (Fig. 7). Males showed this pattern strongly. 


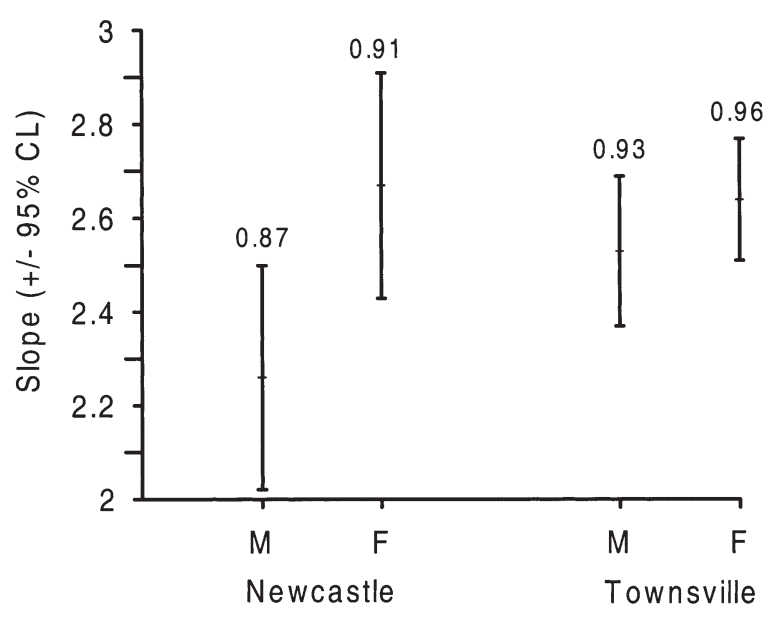

Fig. 6. The slope $( \pm 95 \%$ confidence limits, CL) of the lengthweight relationship for every combination of sex and location. The value above each point is the $r^{2}$ value for each relationship. $\mathrm{M}=$ male, $\mathrm{F}=$ female

Relationship between body size and gonad weight

Males in all seasons had significant linear relationships between testis weight and body weight (Fig. 8). However, the rate of increase in testis weight was slightly greater for the males caught in summer than for the autumn and winter males $(F=9.42$, df 2,336 , p < 0.001).

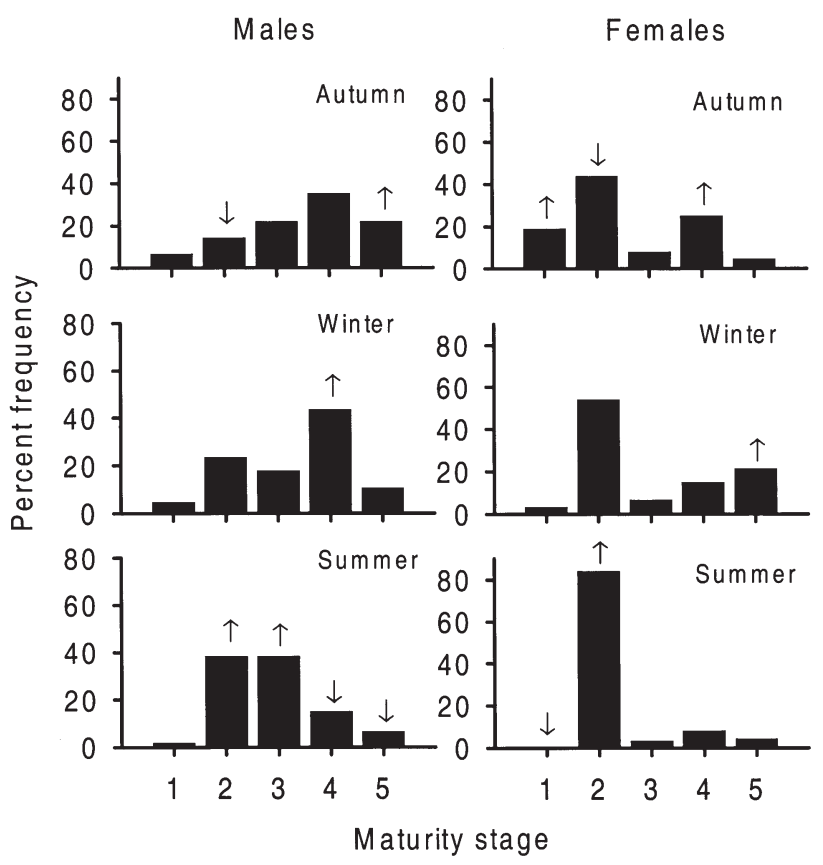

Fig. 7. Maturity stage frequency distributions for Townsville male and female Loliolus noctiluca for each season of capture. The arrows indicate the direction in which the observed frequencies differed from expected frequencies generated under the assumption that maturity stage is independent of season

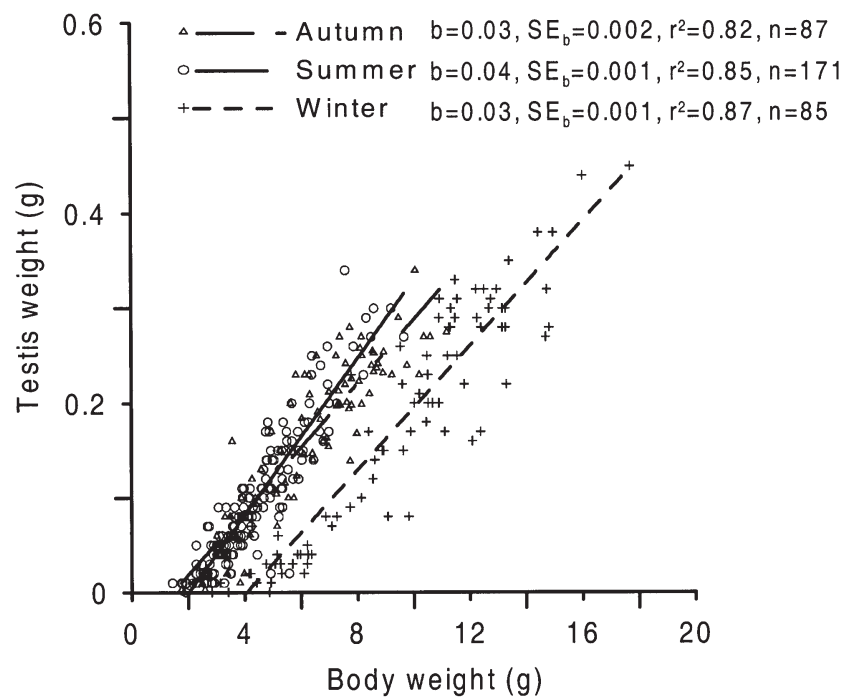

Fig. 8. Relationship between body weight and testis weight for male Loliolus noctiluca for each season of capture. $\mathrm{b}=$ growth rate, $\mathrm{SE}_{\mathrm{b}}=$ standard error of $\mathrm{b}$

The summer-caught females showed no linear relationship between body weight and ovary weight $(F=$ 3.35 , df $1,19, p=0.083$ ). However, both the winter and autumn-caught females did show linear relationships, although a comparison of the linear relationships revealed no difference $(F=1.75$, df $1,49, \mathrm{p}=0.192)$ so the data were combined (Fig. 9).

\section{Age and size at maturity}

The average weight and length of mature individuals was dependent upon season for both sexes (Sex $\times$

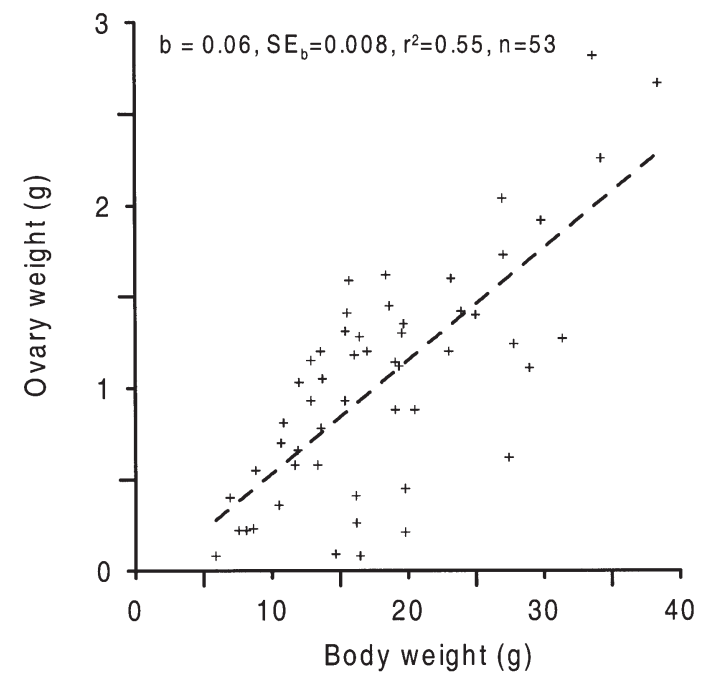

Fig. 9. Relationship between body weight and ovary weight for autumn and winter females of Loliolus noctiluca. $\mathrm{b}=$ growth rate, $\mathrm{SE}_{\mathrm{b}}=$ standard error of $\mathrm{b}$ 
season interaction $F_{\text {weight }}=39.66$, df 2,190, p $<0.001$; $F_{\mathrm{ML}}=8.15$, df 2,190, $\mathrm{p}<0.001$ ). In the case of both males and females the average length and weight of mature autumn and summer-caught squid was approximately $40 \%$ smaller than the average size of mature, winter-caught squid (Fig. 10).

The average age of mature males was $77.5 \mathrm{~d}$ (SE 11.07) compared with the females who at $83.1 \mathrm{~d}$ (SE 9.75) were on average $7 \%$ older $(F=8.07$, df 1,138 , $\mathrm{p}=0.005)$. Both sexes showed similar differences in average age of mature individuals $(F=43.64$, df 2,138$)$. Autumn-caught squid at $71.5 \mathrm{~d}$ (SE 7.1) were on average $23 \%$ younger than winter-caught squid (mean $88.2 \mathrm{~d}, \mathrm{SE}$ 8.8). The summer-caught squid were intermediate in age (mean 81.5 d, SE 9.6).

\section{DISCUSSION}

This study helps to provide a better understanding of the growth and maturity dynamics of Loliolus noctiluca and presents an interesting parallel to previous work on Lolliguncula brevis (Jackson et al. 1997). These 2 species appear to be ecological equivalents. They are similar in body size and shape, inhabit shallow inshore waters and both seem to have considerable tolerance for variation in salinity and temperature (Hendrix et al. 1981, Lu et al.
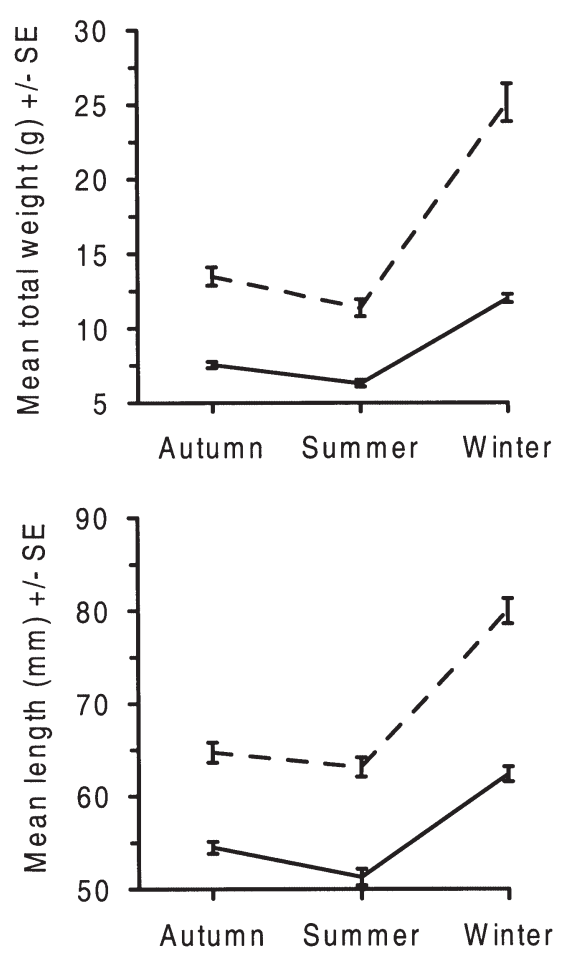

Fig. 10. Average weight and mantle length of mature male (-) and female (- - - Loliolus noctiluca in each of the 3 seasons
1985, Mangum 1991). Interestingly, the general shape and translucency of the tropical $L$. noctiluca statoliths are similar in appearance to L. brevis. However, the statoliths for L. noctiluca from Newcastle were not as translucent and required grinding on both anterior and posterior surfaces.

It appears that the Schnute (1981) model was particularly suitable for the modelling of growth in Loliolus noctiluca due to the variable form of the growth curve depending on sex and season. It was particularly useful in our analysis as some of the size-at-age plots showed some ambiguity about the presence of an asymptote. However, with the Schnute (1981) model we were able to indicate that growth was not asymptotic for any sex or season.

Initial statolith age data for Loliolus noctiluca were published in Jackson \& Choat (1992) from individuals captured between May and July 1989. The growth data presented in that paper are similar to the winter samples in this study. Lolliguncula brevis has very clear seasonal patterns of growth, presumably as a result of changes in seasonal temperatures (Jackson et al. 1997). L. brevis that hatched during summer had much faster growth and a shorter lifespan than individuals that hatched during cooler periods of the year. Furthermore, there was no dramatic difference in individual size for the different seasonal cohorts, they just took longer to get to a similar size. The results of Jackson et al. (1997) corroborated initial suggestions by Forsythe (1993) that relatively small variations in temperature (especially during the juvenile growth phase) can have dramatic impacts on growth rates. Current consensus is that higher temperatures accelerate squid growth (e.g., Forsythe et al. 2001). However, this apparently is not the situation with $L$. noctiluca off Townsville. Over a very large latitudinal scale (tropical Townsville versus temperate Newcastle) there was an obvious slowing of growth and lengthening of lifespan. Our Townsville/Newcastle comparison resulted in similar results to seasonal samples of $L$. brevis captured off the Texas coast by Jackson et al. (1997). However, our comprehensive temporal data set from Townsville presents a different picture of squid growth from the spatial pattern. Growth was plastic with different growth models needed for describing growth.

The pattern of growth rate and body size in the different seasons was not predicted from the literature. Individuals growing through the coolest period of the year had faster growth rates than those individuals that grew during warmer periods. This was not due to the influence of hatching period. Back-calculating and regrouping the data by season of hatching did not greatly modify the results. As a result of the short lifespan of Loliolus noctiluca, individuals essentially grow through a single season. 
The faster growing squid that achieved the largest sizes were females that grew through winter. This is especially apparent in females where both summer and winter populations live for ca $100 \mathrm{~d}$ but the wintercaught females are ca $35 \mathrm{~g}$ whereas the summer-caught females are ca $15 \mathrm{~g}$. The body size of autumn-caught females is intermediate between summer and winter. Lower temperatures appear to provide conditions that promote faster growth and result in females outgrowing their summer counterparts. Body size is much smaller in males but a similar pattern is apparent.

Winter squid do not just get there faster, they keep growing to achieve a much larger body size by the time they get to the end of their lifespan (100 to $125 \mathrm{~d}$ ). This finding was unexpected as current theory hypothesised that warmer temperature would have accelerated growth (e.g., Forsythe 1993, Jackson et al. 1997, Forsythe et al. 2001). There are clearly other factors controlling the growth of Loliolus noctiluca. Rocha \& Guerra (1999) found a similar pattern in Loligo vulgaris off Galicia, Spain. Winter/spring-hatched individuals of $L$. vulgaris attained a larger size at the same age than summer/autumn-hatched individuals. They attributed this to better feeding conditions later in life during the summer-autumn period due to coastal upwelling. Thus, these squid did not appear to be disadvantaged from hatching in a cooler period. However, this example is still not directly related to what is happening with L. noctiluca in Australia as this species has a much shorter lifespan with a winter-hatched squid dying before experiencing summer temperatures.

Due to the wide distribution of Loliolus noctiluca, it is possible that a more temperate environment may be its 'ideal' habitat. Thus, squid off North Queensland in summer may be at their physiological limits with respect to temperature, resulting in reduced growth rates. The small short-lived tropical sepioid Idiosepius pygmaeus, also inhabits similar environments in North Queensland (Jackson 1989). However, based on visual surveys, I. pygmaeus is much more abundant in nearshore habitats during the cooler period of the year and almost disappears from these habitats during the warm summer periods (Jackson 1991). Surface water temperatures in Cleveland Bay off Townsville range from around $19^{\circ} \mathrm{C}$ in July to over $30^{\circ} \mathrm{C}$ in January (Walker 1981). It appears that $I$. pygmaeus cannot tolerate warm shallow summer temperatures and may migrate into deeper waters (Jackson 1992). Moreover, based on statolith age analysis of $I$. pygmaeus, females had the greatest mean growth rates during the cooler months of May and June (Jackson \& Choat 1992) which parallels our results with $L$. noctiluca.

A possible explanation for the faster growth exhibited in cooler seasons for both Loliolus noctiluca and Idiosepius pygmaeus may be found in O'Dor \& Wells
(1987) and might relate to the inter-relation of temperature, feeding rate and metabolism. If the metabolic rate at any given size or temperature exceeds digestion rate, then there is less growth potential. A decrease in temperature will decrease metabolic rate. If a decrease in temperature decreases metabolic rate faster than digestion rate, then there will be an increase in growth potential. If digestion rate is limiting, then anything that elevates metabolic rate (such as temperature) could decrease growth potential. This may be especially relevant to small squid since small squid have higher feeding and digestion rates than large squid (O'Dor \& Wells 1987). This has been explored experimentally in a juvenile tropical cuttlefish, in which it was found that juveniles at higher temperatures grew fastest, but this was influenced by ration level (Moltschaniwskyj \& Martinez 1998).

The faster growth rate and larger body size in the winter observed for Loliolus noctiluca may be related to food supply. Prey for L. noctiluca may be more abundant and available during the winter rather than the summer. The sergestid crustacean Acetes sibogae australis appears to be an important prey for L. noctiluca as it readily feeds on this crustacean in captivity (Jackson 1990). Moreover, A. sibogae is abundant during cooler periods of the year off Townsville (Jackson 1991, 1992).

The autumn Newcastle population essentially grew slower, lived longer and achieved a larger body size than the autumn Townsville squids. However, the size of the winter Townsville squids was more similar to the Newcastle sample although the oldest Newcastle individuals were older than any Townsville squid. The southern population appeared to have an extended lifespan compared to their northern counterparts. Dimmlich \& Hoedt (1998) provide size-at-age information for Loliolus noctiluca from considerably further south in Australian waters off the Victorian coast. Interestingly, the maximum body size for the Victorian population was similar to our data for the Newcastle squid. However, the maximum age reported by Dimmlich \& Hoedt (1998) was much greater (up to 257 d) than Newcastle squid (148 d) or Townsville squid (121 d). This suggests that there might be a positive relationship between lifespan and latitude in $L$. noctiluca populations. Lifespan appears to increase in concert with increasing latitude.

We do, however, doubt the validity of the form of growth that Dimmlich \& Hoedt (1998) describe for Loliolus noctiluca in Victoria. These authors modelled growth using an asymptotic logistic curve. While their data certainly appear asymptotic, it is highly probable that this was caused from pooling size-at-age data from individuals collected over an extended period. The squid aged in the work by Dimmlich \& Hoedt 
(1998) were collected between December and April. Squid collected over such a long period would have experienced very different growth conditions. By pooling size-at-age data collected over different seasonal periods, Jackson (1998, Fig. 4) showed that it is possible to produce a relationship that is asymptotic but an artefact.

Ageing individuals provides a means to better understand the dynamics of maturation. Our study revealed that maturity as well as growth was dependent on season, which is also characteristic of Australian populations of Sepioteuthis (Pecl 2001). However, there was considerable variability in our data, which makes drawing definitive conclusions difficult. An organism with such a short lifespan as Loliolus noctiluca off Townsville has to rely on reproduction throughout the year and at any one time there will be a number of overlapping generations. This feature has also been noted in other tropical loliginids including Photololigo sp. ${ }^{1}$ in Australia (Jackson 1993), Loligo sanpaulensis in Brazil (Andriguetto \& Haimovici 1996), L. chinensis and L. duvauceli in Thailiand (Chotiyaputta 1997) and L. vulgaris off both the Saharan Bank (Raya et al. 1999) and the Saharan Shelf (Arkhipkin 1995). This strategy has been suggested as being a common feature in some small sepiolids and tropical species which have been described as having 'almost aseasonal continuous recruitment' (see Boyle \& Boletzky 1996, Fig. 1d). The reproductive activity of some temperate loliginids can also spread throughout a considerable period of the year (eg., Loligo forbesi in the North Atlantic, Boyle et al. 1995, Collins et al. 1995a,b, 1997 and Loligo vulgaris reynaudii off South Africa, Augustyn et al. 1994) with mature individuals present over 6 to 7 mo of the year.

The influence of season on gonad investment in Loliolus noctiluca could only be detected in males, with the autumn-caught males having the greatest gonad growth. Our study suggests that the different seasonal growing conditions do not affect the ovary-soma relationship in females. Season, however, does have a marked effect on age and size-at-maturity. The only consistent trends in this study were a delay in maturity in both sexes in winter and a markedly smaller size in mature individuals of both sexes in summer. This was especially apparent in females where mature individuals in summer were less than half the weight of autumn or winter ones.

Variation in maturity has been documented in the loliginids Photololigo sp. (previously referred to as Loligo chinensis, see footnote), (Jackson 1993) and Lol-

\footnotetext{
${ }^{1}$ For taxonomic status of Photologio sp. (previously referred to as Loligo chinensis, Jackson \& Choat 1992, Jackson 1993) off North Queensland see Jackson \& Yeatman (1996)
}

liguncula brevis (Jackson et al. 1997). The pattern of maturity in these 2 loliginids is different from that of Loliolus noctiluca. Both Photololigo sp. in Townsville and $L$. brevis in the Gulf of Mexico show accelerated maturation and shorter lifespans in warmer seasons, without appreciable differences in body sizes. Raya et al. (1999) also found considerable flexibility in size-atmaturity throughout the year but did not explore this in relation to age. An examination of seasonal maturity and patterns in the sepioid Idiosepius pygmaeus (Jackson 1993) revealed no seasonal differences in body size, but appreciable differences in ages and gonad weights depending on season. Cooler season (spring) individuals lived longer and had larger gonads than their warm-season (autumn) counterparts. The results of our study along with previous work indicate that it is currently difficult to highlight any consistent seasonal maturity patterns in warm water and tropical squids, and sepioids. Furthermore, warm water and tropical loliginids reveal that time scales of lifespans and spawning events can be much shorter (on the order of a few months) than the more generalised annual loliginid patterns suggested in earlier work (Boyle et al. 1995).

Acknowledgements. We would like to thank Ron O'Dor for useful discussion regarding the dynamics of squid growth and Jayson Semmens for going out of his way to collect squids for us during teaching trips aboard the James Kirby. This research was supported by an ARC Large Grant (A0960152).

\section{LITERATURE CITED}

Andriguetto JM, Haimovici M (1996) Reproductive cycle of Loligo sanpaulensis Brakoniecki, 1984 (Cephalopoda; Loliginidae) in southern Brazil. Sci Mar 60:443-450

Arkhipkin AI (1994) Age, growth and maturation of the squid Enoploteuthis leptura (Oegopsida: Enoploteuthidae) from the central-east Atlantic. J Moll Stud 60:1-8

Arkhipkin A (1995) Age, growth and maturation of the European squid Loligo vulgaris (Myopsida, Loliginidae) on the West Saharan Shelf. J Mar Biol Assoc UK 75:593-604

Arkhipkin AI (1998) Age and growth of the squid Abraliopsis pfefferi (Oegopsida: Enoploteuthidae) from the centraleast Atlantic based on statolith microstructure. Sci Mar 60: 325-330

Augustyn CJ, Lipinski MR, Sauer WHH, Roberts MJ, Mitchell-Innes BA (1994) Chokka squid on the Agulhas Bank: life history and ecology. South Afr J Sci 90:143-154

Boyle PR, Boletzky Sv (1996) Cephalopod populations: definition and dynamics. Phil Trans R Soc Lond B 351:985-1002

Boyle PR, Pierce GJ, Hastie LC (1995) Flexible reproductive strategies in the squid Loligo forbesi. Mar Biol 121: 501-508

Brodziak JKT, Macy WK III (1996) Growth of long-finned squid, Loligo pealei, in the northwest Atlantic. Fish Bull 94:212-236

Chen Y, Jackson DA, Harvey HH (1992) A comparison of vonBertalanffy and polynomial functions in modelling fish growth data. Can J Fish Aquat Sci 49:1228-1235 
Chotiyaputta C (1997) Distribution, abundance, reproductive biology, age and growth of Loligo chinensis and Loligo duvauceli in the western Gulf of Thailand. In: Hancock D, Smith DC, Grant A, Beumer JP (eds) Developing and sustaining world fisheries resources; the state of science and management. CSIRO Publishing, Collinwood, p 614-619

Collins MA, Burnell GM, Rodhouse PG (1995a) Recruitment, maturation, and spawning of Loligo forbesi Steenstrup (Cephalopoda: Loliginidae) in Irish waters. ICES J Mar Sci 52:127-137

Collins MA, Burnell GM, Rodhouse PG (1995b) Reproductive strategies of male and female Loligo forbesi (Cephalopoda: loliginidae). J Mar Biol Assoc UK 75:621-634

Collins MA, Pierce GJ, Boyle PR (1997) Population indices of reproduction and recruitment in Loligo forbesi (Cephalopoda: Loliginidae) in Scottish and Irish waters. J Appl Ecol 34:778-786

Dawe EG, Beck PC (1991) Population structure, growth, and sexual maturation of short-finned squid (Illex illecebrosus) at Newfoundland. Can J Fish Aquat Sci 54:137-146

Dimmlich WF, Hoedt FE (1998) Age and growth of the myopsid squid Loliolus noctiluca in Western Port, Victoria, determined from statolith microstructure analysis. J Mar Biol Assoc UK 78:577-586

Forsythe JW (1993) A working hypothesis on how seasonal temperature change may impact the field growth of young cephalopods. In: Okutani T, O'Dor RK, Kubodera T (eds) Recent advances in cephalopod fisheries biology. Tokai University Press, Tokyo, p 133-143

Forsythe JW, Walsh LS, Turk PE, Lee PG (2001) Impact of temperature on juvenile growth and age at first egg-laying of the Pacific reef squid Sepioteuthis lessoniana reared in captivity. Mar Biol 138:103-112

Grist EPM, des Clers S (1998) How seasonal temperature variations may influence the structure of annual squid populations. IMA J Math Appl Med Biol 15:189-209

Hatfield EMC (2000) Do some like it hot? Temperature as a possible determinant of variability in the growth of the patagonian squid, Loligo gahi (Cephalopoda: Loliginidae). Fish Res 47:27-40

Hendrix JP Jr, Hulet WH, Greenberg MJ (1981) Salinity tolerance and the responses to hypoosmotic stress of the bay squid Lolliguncula brevis, a euryhaline cephalopod mollusc. Comp Biochem Physiol A Comp Physiol 69:641-648

Jackson GD (1989) The use of statolith microstructures to analyse life-history events in the small tropical cephalopod Idiosepius pygmaeus. Fish Bull 87:265-272

Jackson GD (1990) The use of tetracycline staining techniques to determine statolith growth ring periodicity in the tropical loliginid squids Loliolus noctiluca and Loligo chinensis. Veliger 33:395-399

Jackson GD (1991) Age growth and population dynamics of tropical squid and sepioid populations in waters off Townsville, North Queensland, Australia. PhD thesis, James Cook University of North Queensland

Jackson GD (1992) Seasonal abundance of the small tropical sepioid Idiosepius pygmaeus (Cephalopoda, Idiosepiidae) at two localities off Townsville, North Queensland, Australia. Veliger 35:396-397

Jackson GD (1993) Seasonal variation in reproductive investment in the tropical loliginid squid Loligo chinensis and the small tropical sepioid Idiosepius pygmaeus. Fish Bull 91:260-270

Editorial responsibility: Otto Kinne (Editor),

Oldendorf/Luhe, Germany
Jackson GD (1994) Application and future potential of statolith increment analysis in squids and sepioids. Can J Fish Aquat Sci 51:2612-2625

Jackson GD (1998) Research into the life history of Loligo opalescens: where to from here? Calif Coop Oceanic Fish Invest Rep 39:101-107

Jackson GD, Choat JH (1992) Growth in tropical cephalopods; an analysis based on statolith microstructures. Can J Fish Aquat Sci 49:218-228

Jackson GD, Moltschaniwskyj NA (1999) Tests for precision in squid statolith age estimates of Photololigo (Cephalopoda: Loliginidae) off Queensland, Australia. ICES J Mar Sci 56:221-227

Jackson GD, Moltschaniwskyj NA (2001) The influence of ration level on growth and statolith increment width of the tropical squid Sepioteuthis lessoniana (Cephalopoda: Loliginidae): an experimental approach. Mar Biol 138: 819-825

Jackson GD, Yeatman J (1996) Variation in size and age-atmaturity in Photololigo from the North West Shelf of Australia. Fish Bull 94:59-65

Jackson GD Forsythe JW, Hixon, Hanlon RF (1997) Age, growth and maturation of Lolliguncula brevis (Cephalopoda: loliginidae) in the Northwestern Gulf of Mexico with a comparison of length-frequency vs statolith age analysis. Can J Fish Aquat Sci 54:2920-2929

Lu CC, Roper CFE, Tait W (1985) A revision of Loliolus (Cephalopoda; Loliginidae), including L. noctiluca, a new species of squid from Australian waters. Proc R Soc Vict 97:59-85

Mangum CP (1991) Salt sensitivity of the hemocyanin of euryand stenohaline squids. Comp Biochem Physiol A Comp Physiol 99:159-161

Moltschaniwskyj NA, Martinez P (1998) Effect of temperature and food levels on the growth and condition of juvenile Sepia elliptica (Hoyle 1885): an experimental approach. J Exp Mar Biol Ecol 229:289-302

O'Dor RK, Wells MJ (1987) Energy and nutrient flow In: Boyle PR (ed) Cephalopod life cycles, Vol II. Academic Press, London, p 109-133

Pecl G (2001) Flexible reproductive strategies in tropical and temperate Sepioteuthis squids. Mar Biol 138:93-101

Raya CP, Balguerías E, Fernández-Núñez, Pierce GJ (1999) On reproduction and age of the squid Loligo vulgaris from the Saharan Bank (north-west African coast). J Mar Biol Assoc UK 79:111-120

Rocha F, Guerra A (1999) Age and growth of two sympatric squid Loligo vulgaris and Loligo forbesi, in Galician waters (north-west Spain). J Mar Biol Assoc UK 79:697-707

Rodhouse PG, Hatfield EMC (1990a) Age determination in squid using statolith growth increments. Fish Res 8: 323-334

Rodhouse PG, Hatfield EMC (1990b) Dynamics of growth and maturation in the cephalopod Illex argentinus de Castellanos, 1960 (Teuthoidea: Ommastrephidae). Phil Trans R Soc Lond B 329:229-241

Schnute J (1981) A versatile growth model with statistically stable parameters. Can J Fish Aquat Sci 38:1128-1140

Walker TA (1981) Annual temperature cycle in Cleveland Bay Great Barrier Reef province. Aust J Mar Freshw Res 32: 987-991

Young RE, Mangold KM (1993) Growth and reproduction in the mesopelagic boundary squid Abralia trigonura. Mar Biol 119:413-421

Submitted: September 13, 2000; Accepted: May 25, 2001

Proofs received from author(s): July 31, 2001 